15. A. Rodri'guez, E. Sanz, E. De Mercado, E. Go'mez, M.Martı'n, C. Carrascosa, E. Go'mez-Fidalgo, D. A. Villago'mez, and R.Sa'nchez-Sa'nchez. 2010. Reproductive consequences of a reciprocal chromosomal translocation in two Duroc boars used to provide semen for artificial insemination. Theriogenology. 74:67-74 (in English).

УДК 636.223.082:591.11

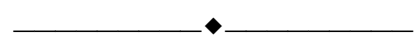

\title{
ИММУНОГЕНЕТИЧЕСКАЯ ХАРАКТЕРИСТИКА СТАДА АБЕРДИН-АНГУССКОЙ ПОРОДЫ
}

\begin{abstract}
А. Г. КОНСТАНДОГЛО ${ }^{1}$, В. Ф. ФОКША ${ }^{\mathbf{1}}$, А. Л. ГОРЯ ${ }^{2}$
${ }^{1}$ Научно-практический институт биотехнологий в зоотехнии и ветеринарной медицине (Максимовка, Республика Молдова)

${ }^{2}$ Крестьянское хозяйство „Юлиана Горя” (Будэй, Республика Молдова)

aliek55@mail.ru
\end{abstract}

В статье приведены результаты изучения животных абердин-ангусской породы по группам крови. Выявлена наибольшая частота встречаемости антигенов $B_{2}, G_{3}, Y_{2}, G^{\prime}, Q^{\prime}, G^{\prime \prime}$ (ЕАВ локус), антигенов $C_{1}, C_{2}, E, W$ и $X_{2}$ (ЕАС локус). Наблюдается высокая частота встречаемости аллеля $B_{1} G_{1}(0,0913)$, который из доступных нам литературных источников встречается только у голштинизированного скота ярославской породы и красной эстонской породы. Гомозиготность анализируемой популяиии абердин-ангусского скота является самой низкой по сравнению с имеющимися в литературе данными и составляет 0,31\%.

Ключевые слова: группы крови, антиген, аллель, частота, абердин-ангусская порода

\section{IMMUNOGENETIC CHARACTERISTIC OF HERD OF THE ABERDIN-ANGUSSIAN BREEDS}

A. G. Konstandoglo', V. F. Foksha ${ }^{1}$, A. L. Gorea ${ }^{2}$

${ }^{1}$ Scientific and Practical Institute of Biotechnologies in Zootechny and Veterinary Medicine (Republic of Moldova)

${ }^{2}$ Peasant farming „Iuliana Gorea”, (Budey, Republic of Moldova)

In the article are presented the results of studied animals of the Aberdeen-Angus breed by blood groups. The highest frequency of antigens $B_{2}, G_{3}, Y_{2}, G^{\prime}, Q^{\prime}, G^{\prime \prime}$ (EAB locus), antigens $C_{1}, C_{2}$, $E, W$ and $X_{2}$ (EAC locus) was detected. It is observed a high frequency of occurrence of the allele $B_{1} G_{1}$ (0.0913), which from available literature sources to us is met only at holsteinized cattle of the Yaroslavl breed and the red Estonian breed. The homozygosis of the analyzed population of Aberdeen-Angus cattle is the lowest in comparison with the data available in the literature and is $0.31 \%$. Keywords: blood groups, antigen, allele, frequency, Aberdeen-Angus breed

\section{ІМУНОГЕНЕТИЧНА ХАРАКТЕРИСТИКА СТАДА АБЕРДИН-АНГУСЬКОӤ ПОРОДИ} О. Г. Констандогло ${ }^{1}$, В. Ф. Фокша ${ }^{1}$, А. Л. Горя ${ }^{2}$

${ }^{1}$ Науково-практичний інститут біотехнології в зоотехнії $і$ ветеринарній медицині (Республіка Молдова)

${ }^{2}$ Селянське господарство "Юліана Горя" (Будей, Республіка Молдова)

У статті наведені результати вивчення тварин абердин-ангуської породи за групами крові. Виявлено найбільша частота народження антигенів $B_{2}, G_{3}, Y_{2}, G^{\prime}, Q^{\prime}, G^{\prime \prime}$ (ЕАВ локус), антигенів $C_{1}, C_{2}, E, W i X_{2}(E A C$ локус). Спостерігається висока частота народження аллеля $B_{1} G_{1}(0,0913)$, який з доступних нам літературних джерел, зустрічається тільки у голштиізованої худоби ярославської породи і червоної естонської породи. Гомозиготність

Розведення і генетика тварин. 2018. Вип. 55 
аналізованої популяциї абердин-ангуської худоби є найнижчою в порівнянні з наявними в літературі даними і становить 0,31\%.

\section{Ключові слова: групи крові, антиген, алель, частота, абердин-ангуська порода}

Введение. Повышенный интерес к мясному скотоводству в последние годы способствовал увеличению численности мясного скота во многих странах мира. Доля мясного скотоводства в общем поголовье крупного рогатого скота в странах Европы и Северной Америки составляет от 40 до 85\% [7]. Наиболее конкурентоспособной специализированной мясной породой мирового значения является абердин-ангусская порода.

Абердин-ангусская порода - одна из классических британских пород, созданная в Шотландии, в горной части страны с суровым климатом, входит в число мясных скороспелых пород мирового значения. Она формировалась из двух отродий местного скота: абердинского с более выраженным мясным типом телосложения и скороспелости, и ангусского - более, чем первый, великорослого и обладающего более высокой молочностью $[17,18]$.

Приспособленность к пастбищному содержанию является важной хозяйственной ценностью породы [19]. Так как в Шотландии откормом мясного скота не занимались, животные выгуливались в течение 2-3 лет на пастбищах, а потом продавались на откорм в Англию. Содержание на пастбищах выработало у животных способность потреблять в большом количестве зеленую массу. Они характеризуются высокой скороспелостью, рано заканчивают рост и проявляют тенденцию к более раннему ожирению по сравнению с другими породами мясного скота. Абердин-ангусы хорошо акклиматизируются в условиях умеренного и холодного климата. Мясные качества животных высокие: мясо нежное, тонковолокнистое, с хорошей мраморностью.

В доступных литературных источниках имеются единичные публикации об исследованиях групп крови абердин-ангусской породы. С. А. Алимова и др. [1] определили антигены групп крови, выявили достоверную зависимость между аллельным составом крови и продуктивностью коров абердин-ангусской породы. Р. Б. Нахушев и др. [11] проанализировали стада абердин-ангусского скота в Кабардино-Балкарии по частоте встречаемости 26 антигенов систем групп крови, выявили различия по антигенам $\mathrm{Q}^{\prime}, \mathrm{W}, \mathrm{F}^{\prime}, \mathrm{L}$, свидетельствующие о достаточной разнородности поголовья скота.

Небольшую партию скота абердин-ангусской породы завезли в Республику Молдова из Румынии (2011) и Германии (2015). В 2017 году поголовье абердин-ангусского скота в стаде крестьянского хозяйства „Юлиана Горя” составляло 149 голов, в том числе 70 коров, 43 телочки и 36 бычков.

Целью наших исследований было дать иммуногенетическую характеристику популяции скота абердин-ангусской породы, импортированную в Республику Молдова.

Материалы и методы исследований. Материалом для исследований послужила кровь, отобранная у животных абердин-ангусской породы в стаде крупного рогатого скота крестьянского хозяйства $(\mathrm{KX})$ „Юлиана Горя” $(\mathrm{n}=115)$. Взятие крови от животных, постановку реакций гемолиза эритроцитов, а также изучение групп крови проводили по общепринятой методике [9]. Группы крови определяли гемолитическими тестами с использованием 49 реагентов крупного рогатого скота, унифицированных в международных сравнительных испытаниях, которыми выявляли антигены, контролируемые аллельными генами 9 генетических систем. Частоты встречаемости антигенов и аллелей ЕАВ-локуса (q) определяли общепринятым методом.

Анализ аллелей ЕАВ-локуса проведен по следующим генетическим показателям: степени гомозиготности $(\mathrm{C} \alpha)$, количеству эффективно действующих аллелей $(\mathrm{Na})$, степени генетической изменчивости (V) [20], общему количеству аллелей локуса, суммарной частоте встречаемости основных и редких аллелей [8].

Результаты исследований. В результате исследований и анализа антигенного спектра групп крови животных абердин-ангусской породы установлено, что носителями антигена $\mathrm{A}_{2}$ 
были 9 животных с частотой встречаемости 0,0783 (табл. 1). Носителей антигена Z' не было выявлено, хотя по некоторым источникам, наличие антигена Z' характерно для животных мясных пород $[2,16]$.

1. Антигенный спектр групп крови жниотных абердин-ангуской породы

\begin{tabular}{|c|c|c|c|c|c|c|c|c|c|}
\hline $\begin{array}{l}\text { № } \\
\text { П/П }\end{array}$ & Локус & Антигены & $\begin{array}{c}\text { Кол-во жи- } \\
\text { вотных }\end{array}$ & Частота & $\begin{array}{l}\text { № } \\
\Pi / \Pi\end{array}$ & Локус & Антигены & $\begin{array}{c}\text { Кол-во жи- } \\
\text { вотных }\end{array}$ & Частота \\
\hline 1. & \multirow[b]{2}{*}{ AEA } & $\mathrm{A}_{2}$ & 9 & 0,0783 & 26. & \multirow[b]{2}{*}{ AEB } & $\mathrm{B}^{\prime \prime}$ & 0 & 0 \\
\hline 2. & & $Z^{\prime}$ & 0 & 0 & 27. & & $\mathrm{G}^{\prime \prime}$ & 44 & 0,3826 \\
\hline 3. & \multirow{23}{*}{ AEB } & $\mathrm{B}_{2}$ & 47 & 0,4087 & 28. & \multirow{10}{*}{ AEC } & $\mathrm{C}_{1}$ & 70 & 0,6087 \\
\hline 4. & & $\mathrm{G}_{2}$ & 34 & 0,2956 & 29. & & $\mathrm{C}_{2}$ & 84 & 0,7304 \\
\hline 5. & & $\mathrm{G}_{3}$ & 57 & 0,4956 & 30. & & $E$ & 90 & 0,7826 \\
\hline 6. & & $\mathrm{I}_{1}$ & 2 & 0,0174 & 31. & & $\mathrm{R}_{1}$ & 4 & 0,0348 \\
\hline 7. & & $\mathrm{I}_{2}$ & 18 & 0,1565 & 32. & & $\mathrm{R}_{2}$ & 28 & 0,2435 \\
\hline 8. & & $\mathrm{O}_{2}$ & 28 & 0,2435 & 33. & & $\mathrm{~W}$ & 77 & 0,6696 \\
\hline 9. & & $\mathrm{P}_{1}$ & 1 & 0,0087 & 34. & & $\mathrm{X}_{1}$ & 37 & 0,3217 \\
\hline 10. & & $\mathrm{P}_{2}$ & 0 & 0 & 35. & & $\mathrm{X}_{2}$ & 51 & 0,4435 \\
\hline 11. & & Q & 0 & 0 & 36. & & $\mathrm{C}^{\prime}$ & 8 & 0,0696 \\
\hline 12. & & $\mathrm{~T}_{1}$ & 13 & 0,1130 & 37. & & $\mathrm{~L}^{\prime}$ & 4 & 0,0348 \\
\hline 13. & & $\mathrm{~T}_{2}$ & 14 & 0,1217 & 38. & \multirow[b]{2}{*}{ F-V } & $\mathrm{F}$ & 64 & 0,5565 \\
\hline 14. & & $\mathrm{Y}_{2}$ & 81 & 0,7043 & 39. & & $\mathrm{~V}$ & 20 & 0,1739 \\
\hline 15. & & $\mathrm{D}^{\prime}$ & 3 & 0,0261 & 40. & $\mathbf{J}$ & $\mathrm{J}_{2}$ & 46 & 0,4000 \\
\hline 16. & & $E_{2}^{\prime}$ & 31 & 0,2696 & 41. & $\mathbf{L}$ & $\mathrm{L}$ & 37 & 0,3217 \\
\hline 17. & & $\mathrm{G}^{\prime}$ & 38 & 0,3304 & 42. & $\mathbf{M}$ & $\mathrm{M}$ & 2 & 0,0173 \\
\hline 18. & & $\mathrm{I}^{\prime}$ & 2 & 0,0174 & 43. & \multirow{6}{*}{$\mathbf{S}$} & $\mathrm{S}_{1}$ & 21 & 0,1826 \\
\hline 19. & & $\mathrm{~J}_{2}^{\prime}$ & 1 & 0,0087 & 44. & & $\mathrm{U}$ & 0 & 0 \\
\hline 20. & & $\mathrm{~K}^{\prime}$ & 2 & 0,0174 & 45. & & $\mathrm{H}^{\prime}$ & 93 & 0,8087 \\
\hline 21. & & $\mathrm{O}^{\prime}$ & 41 & 0,3565 & 46. & & $\mathrm{U}^{\prime}$ & 6 & 0,0522 \\
\hline 22. & & $\mathrm{P}^{\prime}$ & 9 & 0,0783 & 47. & & $\mathrm{H}^{\prime \prime}$ & 4 & 0,0348 \\
\hline 23. & & $\mathrm{Q}^{\prime}$ & 67 & 0,5826 & 48. & & $\mathrm{U}^{\prime \prime}$ & 0 & 0 \\
\hline 24. & & $\mathrm{~T}^{\prime}$ & 0 & 0 & 49. & $\mathbf{Z}$ & $\mathrm{Z}$ & 24 & 0,2087 \\
\hline 25. & & $\mathrm{Y}^{\prime}$ & 10 & 0,0869 & \multicolumn{4}{|c|}{ Средняя частота антигенов } & 0,2346 \\
\hline
\end{tabular}

Следует отметить, что по ЕАВ локусу в анализируемой выборке животных носителей антигенов $\mathrm{P}_{2}, \mathrm{Q}, \mathrm{T}^{\prime}, \mathrm{B}^{\prime \prime}$ не было выявлено. Редкая встречаемость наблюдается по антигенам $\mathrm{P}_{1}$, $\mathrm{J}_{2}{ }_{2} \mathrm{I}_{1}, \mathrm{I}^{\prime}(0,0087-0,0174)$. Наибольшая частота встречаемости выявлена по антигенам $\mathrm{B}_{2}, \mathrm{G}_{3}, \mathrm{Y}_{2}$, $\mathrm{G}^{\prime}, \mathrm{Q}^{\prime}, \mathrm{G}^{\prime \prime}$. В исследованиях В. И. Черкащенко в Калмыкии [16], позднее в экспедиционном обследовании калмыцкой породы С. В. Ухановым и др. [2] также выявлена наибольшая частота встречаемости антигенов $\mathrm{B}_{2}, \mathrm{Y}_{2}$ и Q', что характерно для мясных пород скота.

По ЕАС локусу выявлено 10 антигенов, к наиболее часто встречающимся относятся антигены $\mathrm{C}_{1}, \mathrm{C}_{2}, \mathrm{E}, \mathrm{W}$ и X $\mathrm{X}_{2}$, реже - антигены $\mathrm{R}_{1}(0,0348)$, L' $(0,0348)$ и $\mathrm{C}^{\prime}(0,0696)$.

По $\mathrm{F}-\mathrm{V}$-локусу частоты встречаемости антигенов $\mathrm{F}$ и $\mathrm{V}$ составили соответственно 0,5565 и 0,1739 , однако для некоторых пород мясного направления продуктивности, таких как бурятский и калмыцкий скот, частота их встречаемости колеблется в пределах 0,8940-0,9760 и 0,3230-0,5080 соответственно, [16].

В однофакторных EAJ-, EAL-, EAM-, EAZ- локусах у анализируемого поголовья животных выявлены все изучаемые антигены. Частота встречаемости антигена $\mathrm{J}_{2}$ составила 0,4000 , антигена $\mathrm{L}-0,3217$, антигена $\mathrm{Z}-0,2087$, наименьшая частота встречаемости антигена $\mathrm{M}-0,0173$.

По AES - локусу из 6 изученных антигенов не удалось обнаружить антигены U и U", наибольшая частота отмечается у животных-носителей антигена $\mathrm{H}^{\prime}(0,8087)$.

Средняя частота антигенов или насыщенность антигенными факторами анализируемой популяции абердин-ангусского скота оказалась на уровне $23,5 \%$. 
В результате проведенных исследований были определены и аллели ЕАВ-локуса, которые в большей степени отражают наследственные особенности животных. В анализируемом стаде абердин-ангусской породы было выявлено 77 аллелей (табл. 2).

\section{2. Аллелофонд ЕАВ локуса крупного рогатого скота абердин-ангусской породы}

\begin{tabular}{|c|c|c|c|c|c|c|c|}
\hline $\begin{array}{l}\text { № } \\
\text { П/П }\end{array}$ & Аллель & $\mathrm{n}$ & Частота & $\begin{array}{l}\text { № } \\
\text { П/П }\end{array}$ & Аллель & $\mathrm{n}$ & Частота \\
\hline 1. & $\mathrm{~B}_{1}$ & 3 & 0,0130 & 40. & $\mathrm{Y}_{2} \mathrm{E}_{2}^{\prime} \mathrm{Y}^{\prime} \mathrm{G}^{\prime \prime}$ & 1 & 0,0043 \\
\hline 2. & $\mathrm{~B}_{1} \mathrm{G}_{1}$ & 21 & 0,0913 & 41. & $\mathrm{Y}_{2} \mathrm{E}_{2}^{\prime} \mathrm{Q}^{\prime}$ & 2 & 0,0087 \\
\hline 3. & $\mathrm{~B}_{1} \mathrm{G}_{1} \mathrm{I}_{1}$ & 1 & 0,0043 & 42. & $\mathrm{Y}_{2} \mathrm{E}_{2}^{\prime} \mathrm{O}^{\prime} \mathrm{G}^{\prime \prime}$ & 2 & 0,0087 \\
\hline 4. & $\mathrm{~B}_{1} \mathrm{P}^{\prime}$ & 1 & 0,0043 & 43. & $\mathrm{Y}_{2} \mathrm{G}^{\prime}$ & 2 & 0,0043 \\
\hline 5. & $\mathrm{~B}_{2} \mathrm{G}_{2} \mathrm{O}_{2}$ & 5 & 0,0217 & 44. & $\mathrm{Y}_{2} \mathrm{G}^{\prime} \mathrm{O}^{\prime}$ & 1 & 0,0043 \\
\hline 6. & $\mathrm{~B}_{2} \mathrm{G}_{2} \mathrm{~T}_{1}$ & 2 & 0,0087 & 45. & $\mathrm{Y}_{2} \mathrm{G}^{\prime} \mathrm{O}^{\prime} \mathrm{Q}^{\prime} \mathrm{G}^{\prime \prime}$ & 1 & 0,0043 \\
\hline 7. & $\mathrm{~B}_{2} \mathrm{G}_{2} \mathrm{Y}_{2}$ & 2 & 0,0087 & 46. & $\mathrm{Y}_{2} \mathrm{G}^{\prime} \mathrm{P}^{\prime} \mathrm{Q}^{\prime} \mathrm{G}^{\prime \prime}$ & 1 & 0,0043 \\
\hline 8. & $\mathrm{~B}_{2} \mathrm{G}_{2} \mathrm{Y}_{2} \mathrm{E}_{2}^{\prime} \mathrm{O}^{\prime}$ & 1 & 0,0043 & 47. & $\mathrm{Y}_{2} \mathrm{G}^{\prime} \mathrm{K}^{\prime} \mathrm{O}^{\prime} \mathrm{Q}^{\prime} \mathrm{G}^{\prime \prime}$ & 1 & 0,0043 \\
\hline 9. & $\mathrm{~B}_{2} \mathrm{Y}_{2} \mathrm{G}^{\prime} \mathrm{O}^{\prime} \mathrm{P}^{\prime} \mathrm{Q}^{\prime} \mathrm{G}^{\prime \prime}$ & 1 & 0,0043 & 48. & $\mathrm{Y}_{2} \mathrm{G}^{\prime} \mathrm{O}^{\prime} \mathrm{Y}^{\prime} \mathrm{G}^{\prime \prime}$ & 1 & 0,0043 \\
\hline 10. & $\mathrm{~B}_{2} \mathrm{O}_{1}$ & 4 & 0,0174 & 49. & $\mathrm{Y}_{2} \mathrm{G}^{\prime} \mathrm{O}^{\prime} \mathrm{G}^{\prime \prime}$ & 4 & 0,0174 \\
\hline 11. & $\mathrm{~B}_{2} \mathrm{O}_{1} \mathrm{Y}_{2} \mathrm{D}^{\prime}$ & 3 & 0,0130 & 50. & $\mathrm{Y}_{2} \mathrm{G}^{\prime} \mathrm{O}^{\prime} \mathrm{Q}^{\prime} \mathrm{G}^{\prime \prime}$ & 1 & 0,0043 \\
\hline 12. & $\mathrm{~B}_{2} \mathrm{O}_{1} \mathrm{Y}_{2} \mathrm{G}^{\prime} \mathrm{P}^{\prime} \mathrm{Q}^{\prime} \mathrm{G}^{\prime \prime}$ & 1 & 0,0043 & 51. & $\mathrm{Y}_{2} \mathrm{G}^{\prime} \mathrm{Y}^{\prime} \mathrm{G}^{\prime \prime}$ & 2 & 0,0087 \\
\hline 13. & $\mathrm{~B}_{2} \mathrm{G}^{\prime}$ & 1 & 0,0043 & 52. & $\mathrm{Y}_{2} \mathrm{G}^{\prime} \mathrm{G}^{\prime \prime}$ & 6 & 0,0261 \\
\hline 14. & $\mathrm{G}_{1}$ & 3 & 0,0130 & 53. & $\mathrm{Y}_{2} \mathrm{G}^{\prime} \mathrm{Q}^{\prime}$ & 3 & 0,0130 \\
\hline 15. & $\mathrm{G}_{1} \mathrm{I}_{1} \mathrm{~T}_{1}$ & 1 & 0,0043 & 54. & $\mathrm{Y}_{2} \mathrm{G}^{\prime} \mathrm{Q}^{\prime} \mathrm{G}^{\prime \prime}$ & 4 & 0,0174 \\
\hline 16. & $\mathrm{G}_{1} \mathrm{O}_{1} \mathrm{I}_{1}$ & 1 & 0,0043 & 55. & $\mathrm{Y}_{2} \mathrm{~K}^{\prime}$ & 1 & 0,0043 \\
\hline 17. & $\mathrm{G}_{1} \mathrm{~T}_{1} \mathrm{O}_{1}$ & 1 & 0,0043 & 56. & $\mathrm{Y}_{2} \mathrm{O}^{\prime}$ & 3 & 0,0130 \\
\hline 18. & $\mathrm{G}_{2} \mathrm{O}_{1}$ & 1 & 0,0043 & 57. & $\mathrm{Y}_{2} \mathrm{O}^{\prime} \mathrm{P}^{\prime}$ & 1 & 0,0043 \\
\hline 19. & $\mathrm{G}_{2} \mathrm{O}_{2} \mathrm{~T}_{1}$ & 1 & 0,0043 & 58. & $\mathrm{Y}_{2} \mathrm{O}^{\prime} \mathrm{P}^{\prime} \mathrm{Q}^{\prime} \mathrm{G}^{\prime \prime}$ & 1 & 0,0043 \\
\hline 0. & $\mathrm{G}_{2} \mathrm{Y}_{2} \mathrm{E}_{1}^{\prime} \mathrm{Q}^{\prime}$ & 12 & 0,0522 & 59. & $\mathrm{Y}_{2} \mathrm{O}^{\prime} \mathrm{Q}^{\prime}$ & 8 & 0,0347 \\
\hline 21. & $\mathrm{G}_{3} \mathrm{~T}_{1}$ & 5 & 0,0217 & 60. & $\mathrm{Y}_{2} \mathrm{O}^{\prime} \mathrm{G}^{\prime \prime}$ & 2 & 0,0087 \\
\hline 22. & $\mathrm{I}_{2}$ & 16 & 0,0696 & 61. & $\mathrm{Y}_{2} \mathrm{P}^{\prime} \mathrm{Q}^{\prime} \mathrm{G}^{\prime \prime}$ & 1 & 0,0043 \\
\hline 23. & $\mathrm{O}_{1}$ & 5 & 0,0217 & 62. & $\mathrm{Y}_{2} \mathrm{Q}^{\prime}$ & 1 & 0,0043 \\
\hline 24. & $\mathrm{O}_{1} \mathrm{Y}_{2} \mathrm{D}^{\prime}$ & 1 & 0,0043 & 63. & $\mathrm{Y}_{2} \mathrm{Y}^{\prime}$ & 2 & 0,0087 \\
\hline 25. & $\mathrm{O}_{1} \mathrm{Y}_{2} \mathrm{E}_{2}^{\prime}$ & 1 & 0,0043 & 64. & $\mathrm{Y}_{2} \mathrm{Y}^{\prime} \mathrm{G}^{\prime \prime}$ & 2 & 0,0087 \\
\hline 26. & $\mathrm{O}_{1} \mathrm{Y}_{2} \mathrm{G}^{\prime} \mathrm{G}^{\prime \prime}$ & 1 & 0,0043 & 65. & $E_{2}^{\prime}$ & 1 & 0,0043 \\
\hline 27. & $\mathrm{O}_{1} \mathrm{E}_{2}^{\prime} \mathrm{Q}^{\prime}$ & 1 & 0,0043 & 66. & $\mathrm{E}_{2}^{\prime} \mathrm{O}^{\prime}$ & 1 & 0,0043 \\
\hline 28. & $\mathrm{O}_{2} \mathrm{Y}_{2} \mathrm{Q}$ & 1 & 0,0043 & 67. & $\mathrm{E}_{2}^{\prime} \mathrm{O}^{\prime} \mathrm{G}^{\prime \prime}$ & 1 & 0,0043 \\
\hline 29. & $\mathrm{O}_{2} \mathrm{G}^{\prime} \mathrm{G}^{\prime \prime}$ & 1 & 0,0043 & 68. & $\mathrm{E}_{2}^{\prime} \mathrm{Q}^{\prime}$ & 2 & 0,0087 \\
\hline 30. & $\mathrm{P}_{1} \mathrm{E}_{2}^{\prime} \mathrm{I}^{\prime} \mathrm{J}_{2}{ }_{2} \mathrm{O}^{\prime} \mathrm{P}^{\prime}$ & 1 & 0,0043 & 69. & $\mathrm{G}^{\prime} \mathrm{Q}^{\prime}$ & 1 & 0,0043 \\
\hline 31. & $\mathrm{~T}_{1} \mathrm{Y}_{1}$ & 1 & 0,0043 & 70. & $\mathrm{G}^{\prime} \mathrm{Q}^{\prime} \mathrm{G}^{\prime \prime}$ & 1 & 0,0043 \\
\hline 32. & $\mathrm{~T}_{1} \mathrm{Y}_{2} \mathrm{G}^{\prime}$ & 1 & 0,0043 & 71. & $\mathrm{I}^{\prime} \mathrm{Q}^{\prime}$ & 1 & 0,0043 \\
\hline 33. & $\mathrm{~T}_{1} \mathrm{Y}_{2} \mathrm{G}^{\prime} \mathrm{O}^{\prime} \mathrm{G}^{\prime \prime}$ & 1 & 0,0043 & 72. & $\mathrm{O}^{\prime}$ & 5 & 0,0217 \\
\hline 34. & $\mathrm{Y}_{2}$ & 3 & 0,0130 & 73. & $\mathrm{O}^{\prime} \mathrm{Q}^{\prime}$ & 2 & 0,0087 \\
\hline 35. & $\mathrm{Y}_{2} \mathrm{D}^{\prime} \mathrm{G}^{\prime} \mathrm{G}^{\prime \prime}$ & 1 & 0,0043 & 74. & $\mathrm{O}^{\prime} \mathrm{G}^{\prime \prime}$ & 1 & 0,0043 \\
\hline 36. & $\mathrm{Y}_{2} \mathrm{E}_{2}^{\prime}$ & 1 & 0,0043 & 75. & $\mathrm{Q}^{\prime}$ & 20 & 0,0870 \\
\hline 37. & $\mathrm{Y}_{2} \mathrm{E}_{1}^{\prime} \mathrm{G}^{\prime} \mathrm{G}^{\prime \prime}$ & 2 & 0,0087 & 76. & $\mathrm{G}^{\prime \prime}$ & 3 & 0,0130 \\
\hline 38. & $\mathrm{Y}_{2} \mathrm{E}_{2}^{\prime} \mathrm{O}^{\prime} \mathrm{Q}^{\prime}$ & 1 & 0,0043 & 77. &, $\mathrm{~b}$, & 2 & 0,0087 \\
\hline 39. & $\mathrm{Y}_{2} \mathrm{E}_{2}^{\prime} \mathrm{O}^{\prime} \mathrm{Y}^{\prime}$ & 1 & 0,0043 & & & & \\
\hline
\end{tabular}

Возможно, большинство аллелей специфичны и уникальны для данной породы, такие, например, как $\mathrm{G}_{1} \mathrm{I}_{1} \mathrm{~T}_{1}, \mathrm{G}_{1} \mathrm{~T}_{1} \mathrm{O}_{1}, \mathrm{G}_{2} \mathrm{O}_{2} \mathrm{~T}_{1}, \mathrm{O}_{2} \mathrm{G}^{\prime} \mathrm{G}^{\prime \prime}, \mathrm{T}_{1} \mathrm{Y}_{2} \mathrm{G}^{\prime} \mathrm{O}^{\prime} \mathrm{G}^{\prime \prime}, \mathrm{Y}_{2} \mathrm{E}_{2}^{\prime} \mathrm{Q}^{\prime}, \mathrm{Y}_{2} \mathrm{~K}^{\prime}$ и ряд других, дальнейшие исследования могут подтвердить, или опровергнуть наши предположения. Анализом установлено, что спектр аллелей довольно широк, так как оцениваемая популяция включает в себя животных из двух разных селекций - немецкой и румынской.

Наблюдается высокая частота встречаемости аллеля $\mathrm{B}_{1} \mathrm{G}_{1}$ (частота 0,0913 ), который из доступных нам литературных источников, встречается только у голштинизированного скота ярославской породы [13] и красной эстонской породы [4]. Следует отметить, что аллель $\mathrm{B}_{1} \mathrm{P}^{\prime}$ является общим для лимузинской, бурой карпатской пород, специфичным для кавказской бурой породы. Аллель $\mathrm{B}_{2} \mathrm{G}_{2} \mathrm{O}_{2}$ (частота 0,0217 ) является общей для многих пород: калмыцкой, 
якутской, симментальской и герефордской пород [2]. Аллель О1 (частота 0,0217) является общей для серой украинской [10] и бурой швицкой пород [14].

Выявлено ряд аллелей, специфичных для других пород. Так, аллели $\mathrm{G}_{2} \mathrm{O}_{2} \mathrm{~T}_{1}$ и $\mathrm{E}_{2} \mathrm{O}^{\prime}$ являются специфичными для холмогорской, калмыцкой пород. Аллель $\mathrm{T}_{1} \mathrm{Y}_{1}-$ для красной горбатовской породы, аллель $\mathrm{Y}_{2} \mathrm{E}_{1} \mathrm{G}^{\prime} \mathrm{G}^{\prime \prime}$ - для популяции симментальской породы Тамбовской области, [6, 15].

Аллель $\mathrm{G}_{2} \mathrm{Y}_{2} \mathrm{E}_{1} \mathrm{Q}^{\prime}$, с частотой встречаемости 0,0522 , как известно, характеризует многие породы черно-пестрого корня молочного направления продуктивности, выявлен также у калмыцкого скота [2]. Высокая частота встречаемости и аллеля Q' $(0,0870)$, которая является общей для другой породы мясного направления продуктивности - герефордской [12]. Аллель $\mathrm{Y}_{2} \mathrm{G}^{\prime} \mathrm{G}^{\prime \prime}$ (частота 0,0261 ) является общей для животных калмыцкой породы [6], якутской породы [5], англерской и красно-бурой латвийской пород [3].

Следует отметить, что нейтральная аллель „b, (частота 0,0087$)$ является общей для калмыцкой, красной горбатовской, серой украинской, многих мясных пород, присутствует в аллелофонде пород черно-пестрого корня [12].

Объективную генетическую характеристику популяции животных абердин-ангусской породы отражают и такие показатели, как коэффициент гомозиготности $(\mathrm{Ca})$, количество эффективных аллелей (Na), степень генетической изменчивости (коэффициент V) (табл. 3).

\begin{tabular}{|c|c|c|}
\hline $\begin{array}{c}\text { № } \\
\text { ח/ח }\end{array}$ & Показатели & \\
\hline 1. & Всего исследовано, гол & 115 \\
\hline 2. & $\begin{array}{c}\text { Количество установленных аллелей: - всего } \\
\text { - основных } \\
\text { - редких }\end{array}$ & $\begin{array}{c}206 \\
136 \\
70\end{array}$ \\
\hline 3. & $\begin{aligned} \text { Суммарная частота аллелей: } & \\
& \text { - основных } \\
& \text { - редких }\end{aligned}$ & $\begin{array}{l}0,5913 \\
0,3043\end{array}$ \\
\hline 4. & Коэффициент гомозиготности, С & 0,0031 \\
\hline 5. & Количество эффективных аллелей, $\mathrm{Na}$ & 322 \\
\hline 6. & Степень генетической изменчивости, V & 100,6 \\
\hline
\end{tabular}

Как видно, концентрация основных аллелей в анализируемой выборке составила 59,3\%, редких - 30,4\% соответственно. Гомозиготность анализируемой популяции скота является самой низкой по сравнению с имеющимися в литературе данными. Так, по сравнению с калмыцкой породой [12], коэффициент гомозиготности анализируемых животных абердин-ангусской породы составляет 0,0031 (уровень гомозиготности 0,31\%). Это говорит об очень высоком генетическом разнообразии данной популяции скота, подтверждением чему служит генофонд разных селекций - немецкой и румынской, более детальные исследования последуют.

Состояние аллелофонда породы по уровню гомозиготности отражается показателем числа эффективных аллелей. Исследованиями установлено, что в популяции животных абердин-ангусской породы число эффективных аллелей достигает 322, что соответствует максимально возможным „гомозиготным” структурам в стаде и отражает состояние гетерозиготности по данному локусу. Степень реализации возможной генетической изменчивости (V) составляет 100,6.

\section{Выводы.}

1. Наибольшую частоту встречаемости по AEB локусу имеют антигены $\mathrm{B}_{2}, \mathrm{G}_{3}, \mathrm{Y}_{2}, \mathrm{G}^{\prime}, \mathrm{Q}^{\prime}$, $\mathrm{G}^{\prime \prime}$, по AEC локусу - антигены $\mathrm{C}_{1}, \mathrm{C}_{2}, \mathrm{E}, \mathrm{W}$ и $\mathrm{X}_{2}$. Частоты встречаемости антигенов $\mathrm{F}$ и $\mathrm{V}$ составили соответственно 0,5565 и 0,1739 .

2. Спектр аллелей АЕВ локуса анализируемой популяции скота абердин-ангусской породы довольно широк, выявлена 71 аллель. Большинство аллелей специфичны и уникальны для данной породы: $\mathrm{G}_{1} \mathrm{I}_{1} \mathrm{~T}_{1}, \mathrm{G}_{1} \mathrm{~T}_{1} \mathrm{O}_{1}, \mathrm{G}_{2} \mathrm{O}_{2} \mathrm{~T}_{1}, \mathrm{O}_{2} \mathrm{G}^{\prime} \mathrm{G}^{\prime \prime}, \mathrm{T}_{1} \mathrm{Y}_{2} \mathrm{G}^{\prime} \mathrm{O}^{\prime} \mathrm{G}^{\prime \prime}, \mathrm{Y}_{2} \mathrm{E}_{2}^{\prime} \mathrm{Q}^{\prime}, \mathrm{Y}_{2} \mathrm{~K}^{\prime}$. 
3. Коэффициент гомозиготности анализируемой популяции абердин-ангусского скота является самой низкой по сравнению с имеющимися в литературе данными $(0,0031)$.

\section{БИБЛИОГРАФИЯ}

1. Алимова, С. А. Иммуногенетический анализ крови стада абердин-ангусской породы / С. А. Алимова, В. М. Габидулин, М.В. Тарасов // Разработка и освоение инноваций в животноводстве : материалы междунар. науч.-практ. конф. / под ред. В. И. Левахина, 24-25 окт. 2013 г. Оренбург. - 2013. - С. 11-13.

2. Генетические особенности якутского аборигенного скота и его помесей / С. В. Уханов, 3. И. Берендяева, В. П. Коваленко, А. А. Истомин // Генетика. - 1990. - Т. 26, № 3. - С. 525530.

3. Дексне, В. Я. Группа крови бурой латвийской и англерской пород и их применение в практическом животноводстве / В. Я. Дексне // Племенное дело в скотоводстве Латвийской ССР. - Рига : Зинайте. - 1988. - С. 60-68.

4. Констандогло, А. Г. Иммуногенетическая характеристика популяции крупного рогатого скота красной эстонской породы / А. Г. Констандогло, В. Ф. Фокша, Т. О. Александрова // Біологія тварин. - 2010. - Т. 12, № 1. - С. 240-246.

5. Коротов, Г. П. Крупный рогатый скот Якутской АССР и методы его улучшения / Г. П. Коротов. - Якутск : Якутскнигоиздат. - 1983. - 150 с.

6. Кульчимова, Г. И. Генетические структуры популяций скота калмыцкой породы по биохимическим маркерам / Г. И. Кульчимова, Ф. Г. Каюмов, Е. А. Кофтун // Сборник научных трудов ВНИИИМС. - Оренбург. - 1989. - С. 73-78.

7. Легошин, Г. П. Повышение эффективности мясного скотоводства в России / Г. П. Легошин // Зоотехния. - 2003. - № 3. - С. 24-26.

8. Меркурьева, Е. К. Генетика с основами биометрии / Е. К. Меркурьева, Г. Н. Шангин-Березовский. - М. : Колос. $-1983 .-400$ с.

9. Методические рекомендации по использованию групп крови для повышения селекционно-племенной работы в молочном животноводстве. - 1983. - Ленинград. -24 с.

10. Мещеряков, В. Я. Групи крові великої рогатої худоби сірої української та білоголової української порід. / В. Я. Мещеряков, Б. Є. Подоба // Молочно-м'ясне скотарство. - 1971. Вип. 24. - С. 7-12.

11. Нахушев, Р. Б. Иммуногенетическая характеристика абердин-ангусского скота в Кабардино-Балкарии / Р. Б. Нахушев, М. Г. Тлейншева, Ф. А. Вологирова // Аграрная Россия : науч.произв. ж. -2015 . - № 3. - С. 16-17.

12. Попов, Н. А. Аллелофонд крупного рогатого скота / Н. А. Попов, Г. В. Ескин // Справочный каталог. - М. - 2000. - С. 300.

13. Попов, Н. А. Эволюционные особенности пород красной масти по аллелям В-локуса групп крови / Н. А. Попов // Доклады Российской академии сельскохозяйственных наук. 1997. - № 5. - C. 31-33.

14. Современное состояние бурой швицкой породы в Российской Федерации и перспективы развития / Д. Н. Кольцов, О. В. Татуева, В. К. Чернушенко, В. И. Цысь, Н. С. Петкевич, В. М. Новиков // 70 лет костромской породе крупного рогатого скота : сб. Костромской ГСХА. - Караваево. - 2014. - С. 24-32.

15. Сорокова, П. Ф. Генетический анализ скрещивания симментальского и красно-пестрого голштинского скота по типам крови / П. Ф. Сороковой, Н. А. Попов, Т. И. Осипова // Повышение продуктивности в молочном и мясном скотоводстве, бюл. науч. раб. Всероссийский институт животноводства. Дубровицы. - Вып. 92. - 1988. - С. 84-89.

16. Черкащенко, В. И. Генетические особенности крупного рогатого скота турано-монгольской группы по полиморфным системам крови в связи с сохранением генофонда : дис...канд. биол. наук / В. И. Черкащенко. - Ленинград-Пушкин. - 1984. - 145 с.

17. Bailey, D. R. Caff survival and prewedning grivt in divergent beef dreedsand / D. R. Bailey // J. anim. sc. - 1981. - Vol. 52. - P. 1244-1245. 
18. Bailey, D. R. Postpartum interval in 10 firstgrosses of beef cows inder drylot and range conditions / D. R. Bailey, E. E. Swierstra, T. Entz // Canad. J. anim. sc. - 1988. - Vol. 4. - P. 1027-1033.

19. Lasley, J. Further information on the inheritance of horns and sears / J. Lasley // Bull-O Vram. - 1979. - P. 40-43.

20. Robertson, A. Blood Grouping in dairy cattle improvement / A. Robertson // Proc. VIIth Intern. Congr. Anim. - Vol. 2. - 1956. - P. 79-83.

\section{REFERENCES}

1. Alimova, S. A., V. M. Gabidulin, and M. V. Tarasov. 2013. Immunogeneticheskij analiz krovi stada aberdin-angusskoj porody - Immunogenetic blood test of herd Aberdeen the Angus breed. Immunogeneticheskij analiz krovi stada aberdin-angusskoj porody. Materialy mezhdunarodnoj nauchno-prakticheskoj konferencii «Razrabotka i osnovanie innovacij v zhivotnovodstve 2425 oktjabrja» - Materials of the international scientifically practical conference „Development and development of innovations in livestock production On October 24-25”. Orenburg. 11-13 (in Russian).

2. Uhanov, S. V., Z. I. Berendjaeva, V. P. Kovalenko, and A. A. Istomin. 1990. Geneticheskie osobennosti jakutskogo aborigennogo skota i ego pomesej - Genetic features of the Yakut aboriginal cattle and its hybrids. Genetika - Genetics science, 26(3):525-530 (in Russian).

3. Deksne. V. Ja. 1988. Gruppa krovi buroj latvijskoj i anglerskoj porod i ih primenenie v prakticheskom zhivotnovodstve - Blood type of brown Latvian and anglersky breeds and their application in practical livestock production. Plemennoe delo v skotovodstve Latvijskoj SSR Breeding matter in cattle breeding of the Latvian SSR. Riga: Zinayte, 60-68 (in Latvia).

4. Konstandoglo, A. G., V. F. Foksha, and T. O. Aleksandrova. 2010. Immunogeneticheskaya kharakteristika populyatsii krupnogo rogatogo skota krasnoy estonskoy porody - Immunogenetic characteristics of the cattle population of the red Estonian breed. Biologija tvarin - J. Biology of animals, Lvov. 12(1):240-246 (in Russian).

5. Korotov, G. P. 1983. Krupnyy rogatyy skot Yakutskoy ASSR i metody ego uluchsheniya - Cattle Yakut ASSR and methods of its improvement. Yakutsk : Yakutsknigoizdat. 150 (in Russian).

6. Kul'chimova, G. I., F. G. Kayumov, and E. A. Koftun. 1989. Geneticheskie struktury populyatsiy skota kalmytskoy porody po biokhimicheskim markeram - Genetic structures of populations of the cattle of the Kalmyk breed on biochemical markers. Sbornik nauchnyh trudov Vserossijskogo nauchno-issledovatel'skogo instituta mjasnogo skotovodstva - Collection of scientific works of the All-Russian Research Institute of meat cattle breeding. Orenburg, 73-78 (in Russian).

7. Legoshin, G. P. 2003. Povyshenie effektivnosti myasnogo skotovodstva v Rossii - Increase in efficiency of meat cattle breeding in Russia. Zootekniya - Animal science. 3:24-26 (in Russian).

8. Merkur'eva, E. K., and G. N. Shangin-Berezovskiy. 1983. Genetika s osnovami biometrii - Genetics with the fundamentals of biometrics. Moscow: Kolos. 400 (in Russian).

9. 1983. Metodicheskie rekomendatsii po ispol'zovaniyu grupp krovi dlya povysheniya selektsionno-plemennoy raboty $v$ molochnom zhivotnovodstve - Methodical recommendations on the use of blood groups to enhance breeding and breeding work in dairy cattle. Leningrad, 24 (in Russian).

10. Meshherjakov, V. Ja., and B. E. Podoba. 1971. Grupy krovi velykoi' rogatoi' hudoby siroi' ukrainskoi ta bilogolovi ukrainskoi porid - Blood types of cattle gray ukrainsy and white-headed Ukrainian breeds. Molochno-m'jasne skotarstvo - Dairy and meat cattle breeding. 24:7-12 (in Ukrainian).

11. Nakhushev, R. B., M. G. Tleynsheva, and F. A. Vologirova. 2015. Immunogeneticheskaya kharakteristika aberdin-angusskogo skota $\mathrm{v}$ Kabardino-Balkarii - Immunogenetic characteristics of Aberdeen-Angus cattle in Kabardino-Balkaria. Agrarnaja Rossija : nauch.-proizv. zh. - Agrarian Russia : scientific-prod. journal. 3:6-17 (in Russian).

12. Popov, N. A., and G. V. Eskin. 2000. Allelofond krupnogo rogatogo skota - Allelophond of cattle. Spravochnyj katalog - Reference catalog. Moscow. 300 (in Russian). 
13. Popov, N. A. 1997. Evolyutsionnye osobennosti porod krasnoy masti po allelyam V-lokusa grupp krovi - Evolutionary features of the red lear species according to alleles of the B-locus of blood grains. Doklady Rossijskoj akademii sel'skohozjajstvennyh nauk - Reports of the Russian Academy of Agricultural Sciences. 5:31-33 (in Russian).

14. Kol'cov, D. N., J. V. Tatueva, V. K. Chernushenko, V. I. Cys', N. S. Petkevich, and V. M. Novikov. 2014. Sovremennoe sostojanie buroj shvickoj porody v Rossijskoj Federacii i perspektivy razvitija - The current state of brown shvitsky breed in the Russian Federation and the prospects of development. "70 let kostromskoj porode krupnogo rogatogo skota". Kostromskaja gosudarstvennaja sel'skohozjajstvennaja akademija - In the collection "70 years to the Kostroma breed of cattle". Kostroma state agricultural academy. Karavayevo. 24-32 (in Russian).

15. Sorokova, P. F., N. A. Popov, and T. I. Osipova. 1988. Geneticheskij analiz skreshhivanija simmental'skogo i krasno-pestrogo golshtinskogo skota po tipam krovi - Genetic analysis of crossing of Simmental and red-motley Holstein cattle according by blood types. "Povyshenie produktivnosti $v$ molochnom i mjasnom skotovodstve", bjulleten' nauchnyh trudov, Vserossijskij institut zhivotnovodstva -"Increasing productivity in dairy and beef cattle", Bulletin of Scientific Works, AllRussian Institute of Animal Husbandry. Dubrovitsy. 92:84-89 (in Russian).

16. Cherkashhenko, V. I. 1984. Geneticheskie osobennosti krupnogo rogatogo skota turano-mongol'skoj gruppy po polimorfnym sistemam krovi v svjazi s sohraneniem genofonda - Genetic features of the cattle of the Turan-Mongolian group on polymorphic blood systems in connection with the preservation of the genofond : dis...kand. biol. nauk - thesis of the PhD. Dr.Sci.Biol. LeningradPushkin. 145 (in Russian).

17. Bailey, D. R. 1981. Caff survival and prewedning grivt in divergent beef dreedsand. J. anim. SC. 52:1244-1245.

18. Bailey, D. R., E. E. Swierstra, and T. Entz. 1988. Postpartum interval in 10 firstgrosses of beef cows inder drylot and range conditions. Canad. J. anim. Sc. 4:1027-1033.

19. Lasley, J. 1979. Further information on the inheritance of horns and sears. Bull-O Vram. 4043.

20. Robertson, A. 1956. Blood Grouping in dairy cattle improvement. Proc. VIIth Intern. Congr. Anim. 2:79-83.

УДК 636.3:575.113/.17

\title{
ГЕНЕТИЧНА ДИФЕРЕНЦАЦІЯ ПОПУЛЯЦІЙ АМУРСЬКОГО САЗАНА ТЗОВ «КАРПАТСЬКИЙ ВОДОГРАЙ» ТА ВАТ «ДОНРИБКОМБІНАТ»
}

\author{
А. Е. МАРІУЦА \\ Інститут рибного господарства НААН (Київ, Україна) \\ mariutsa16@ukr.net \\ Досліджено генетичну структуру амурського сазана за трьома генетико-біохімічними \\ системами крові - трансферин, альбумін, естераза. Встановлений рівень фактичної та \\ очікуваної гетерозиготності, середньої гетерозиготності на локус. \\ Диференціація груп амурського сазана за умовами вирощування $\epsilon$ можливою за \\ розподілом алель них варіантів локусів TF, ALB, EST. \\ Ключові слова: генетична диференціація, амурський сазан, популяція, гетерозиготність, \\ поліморфізм, генетична структура, генетико-біохімічні системи,трансферин, альбумін, \\ естераза
}

Розведення і генетика тварин. 2018. Вип. 55 